\title{
A Study on the Conflicts of Communication Between First Grade Students
}

\author{
Yun-Ok Kim \\ Research Center for Korean Language and Literature Education, Korea National University of Education, Cheongju City, Republic of Korea \\ Email address: \\ drill98@hanmail.net \\ To cite this article: \\ Yun-Ok Kim. A Study on the Conflicts of Communication Between First Grade Students. International Journal of Literature and Arts. \\ Vol. 7, No. 5, 2019, pp. 93-97. doi: 10.11648/j.ijla.20190705.11
}

Received: July 21, 2019; Accepted: August 23, 2019; Published: September 5, 2019

\begin{abstract}
The purpose of this study is to analyze the Conflicts of Communication and to look for suggestions regarding speech communication education. In order to accomplish the purpose of this research, the following questions are constructed: 1. What is the reason behind communicational conflicts among first grade students? 2. How does the conflict between two students' progress? 3. What do the students learn? The study found that the conflicts in the communication among the first grade elementary students were created due to difference in identities and the conflicts created interdependent parties which led to poor way of communication. Conflict between two students go through the process of competition, arbitration 1, arbitration 2, and recuperation. The first grade students learned that the expressing of feelings honestly is important, everyone thinks differently and in a conflict, the ability to sympathize is important. The results of this study will help students in listening and speaking skills.
\end{abstract}

Keywords: Communication, Conflict, Identity, Relation, Feeling-Expression

\section{Introduction}

In order to teach the students communication skills effectively, it is important to understand the reality of the students' communication skills and based on that, the content and method of education can be searched and constructed. School is where students spend most of their time after time spent sleeping. The communication skills between and among students show clearly the reality of communications. Students form relationships through communicating, and those relationships change as students experience conflict. The students' experiencing of resolving communicational conflicts affects the students' communication style and formation of relationships.

In recent years, the study of the Conflicts of Communication has become a hot topic in the field of communication education research, such as Cho. J. Y. and Seo. S. H.'s “A Study on Conflict Recognition Survey in the Peer-to-Peer Communication Process of the First Grade Middle School Students" [1], Kim. C. B.'s “A Study on the Consciousness of Responses to Conflicts and the Education of Personality" [2], Jeon. Y. G.'s "A Study of Education Contents for Conversational Strategies of Elementary School
Students' Conflict Conversation: Focusing on Types of Conflict Conversation" [3], etc. The author also tried to explore the recognition and solution process of conflicts of Communication.

The purpose of this study is to perform a qualitative analysis on the communicational conflicts that arise among first grade students. The communicational conflicts present in a classroom of first graders at elementary school A in Sejong City were observed and analyzed. During the conflicts, the students' cognition and reaction were observed and analyzed the underlying meaning. The researcher, over the course of two months (Sept'18-Oct'18), observed the participants as well as hold in-person interviews to gather data for analysis, and continued the research. In the midst of beginning this research, there are several questions the researcher started having:

What is the reason behind communicational conflicts among first grade students?

How does the conflict between two students progress?

What do the students learn during and after the conflict? 


\section{Main Cause of Conflict Among First Grade Students}

\subsection{The Conflict}

A and B are first grade girls and are classmates. After class, they attend Robotics and dance class as extracurricular activities together. On September 16, 2018, A, with a lot of things to carry, asked B to go to extracurricular activities together but B didn't hear A and ended up heading out to the extracurricular activities room without A. Realizing B had left without waiting for A, A rushed to follow after B and in the process, A drops her air plane and cracks the front. A becomes upset at B. Next day, A blames B and tells B that because of $\mathrm{B}$, her plane model cracked, and this develops into a conflict. C, both A and B's friend, mediates and determines it is both of their fault. A and B don't agree with C, so C's mediation is fruitless. Then the teacher approaches A and B and mediates. A and B share what was on their heart and shares with one another their honest feelings. After this, A and $\mathrm{B}$ return to normal and become friends again.

\subsection{Analysis of Cause of Conflict}

Communication is too continuous and complex to go smoothly all the time. No set of events as complicated as human communicating can possibly be completely trouble free, and "conflict" is the general term for these troubles [4]. All conflicts are a partial result of crash of identities. Conflicts arise in the process of participants' means of communications based on identity.

\subsubsection{Identity Composition}

The process of communication is comprised of and based on identity, and the participants themselves participate with their own unique lifestyle or with the world stemmed from the unique lifestyle. Through communication, humans form their identity and relationships with one another [5]. Relationships are live existence and system and it is deemed the daily communication among the participants itself is a relationship. The participants express what they mean to each other while forming and modifying their relationships [6]. The main element of interpersonal relationship is communication because through communication humans form, maintain, and develop relationships [7]. It can be seen that conflicts are formed due to association of different identities during the formation of participants' relationships with each other. Identity is formed by applying it to self or when it is applied by someone else.

Dialogue 1

(Date: September 17, 2018)

A: Hey B! I asked you to wait for me but because you didn't wait and left, I rushed to follow after you, so that's why the plane fell off and this end is broken. The plane is broken because you decided to not wait for me and leave.

B: I just left because I didn't want to be late to the dance practice

A: All this happened because you didn't wait. (Glares at B).
B: (Stares at A while touching own hair)

(Silence as A and B stare at each other)

In this dialogue, it can be said that there has been a conflict due to difference in recognition of identities. A is applying the heartless character/identity who left without waiting to B while communicating. But B is rejecting the negative identity that is being applied to oneself and is applying the punctual and positive identity to oneself.

The communicational conflict is created due to the difference of identity $\mathrm{A}$ is applying on $\mathrm{B}$, and $\mathrm{B}$ is applying on $\mathrm{B}$ oneself. With the negative identity $\mathrm{A}$ is applying on $\mathrm{B}, \mathrm{A}$ is criticizing $\mathrm{B}$ while $\mathrm{B}$ is confused as to A's negative identity of betrayal that was applied to B while all B was trying to do was be punctual and not be tardy. They both are disconcerted. A glares at B with silence. Silence, in this situation, translates to $A$ and $B$ both are upset with each other and are competing.

Dialogue 2

C: Both of you, come here. Tell me what's going on.

A: After Robotics, I asked B to wait for me but B left without waiting for me. I tried to go after B and I tried rush after her. I had a lot of stuff, so in the process I dropped by air plane model so the end of the plane broke off.

B: I just left early to make it to the dance practice in time.

$\mathrm{C}$ : Both of you are at fault. B, you are in the wrong for not waiting, and $\mathrm{A}$, you are in the wrong for getting upset at B.

A: No, I had a lot of stuff to carry so that's why I asked B to wait for me, but because B didn't wait and I was trying to rush after her, I dropped the plane and my plane is broken now.

B: No, I just left so I won't be tardy.

(A and $\mathrm{B}$ continue accusing and defending while the mediator says it's both A and B's fault)

$\mathrm{C}$ sees the conflict between $\mathrm{A}$ and $\mathrm{B}$ and intervenes. $\mathrm{C}$ asks $\mathrm{A}$ and $\mathrm{B}$ to come and listens to them. After listening to both stories, C tells A and B that both of them are at fault; B is in the wrong for not waiting, and $\mathrm{A}$ is in the wrong for getting upset at $\mathrm{B}, \mathrm{C}$ sees that both $\mathrm{A}$ and $\mathrm{B}$ are at fault. $\mathrm{C}$ applies negative identities to both $\mathrm{A}$ and $\mathrm{B}$ : the angered character and identity to A and unreliable character and identity to B, which results in both of their identity and reputation being harmed. $\mathrm{A}$ and $\mathrm{B}$, after hearing what C's opinion regarding their conflict, they refuse C's judgment and retaliates by repeating their opinions.

Dialogue 3

(Teacher confronts A and B regarding the situation).

T: Alright, you two, what is going on?

A: I asked B to wait for me but B just left without me. So I rushed out to follow after and because I had a lot of stuff to carry and was in a rush, I dropped my plane and it broke right here.

B: I only left so that I won't be late to dance practice.

T: Oh I see, A, you must have been upset that your plane cracked.

A: (Nods).

B: I just left because I can't be late.

A: You wouldn't have been late.

B: I didn't know. 
T: I see, B, you left because you were afraid you'd be late, right?

B: Yes.

T: But in this situation, nobody is at fault. Everyone is different. A, you asked B to wait for you but B didn't wait for you which upset you, right?

A: Yes, that's right.

T: On top of that, you cracked your plane while trying to run after B. How upsetting...

A: (Nods).

T: But B didn't want to be late to dance practice so B left. $\mathrm{B}$, did you hear A calling for you?

B: No.

T: I see, B didn't hear anything. So A, can you tell me how you felt when B left without waiting? Did the plane really crack and break because of $\mathrm{B}$ ?

A: (Shakes head - negative).

T: That's correct, it isn't B's fault but A, you were upset, so you can share with B how you felt. Okay? Do you want to try?

A: Hey B, I was upset because you didn't wait for me. Can you wait for me next time?

B: Okay.

T: Would you like to add anything else?

A and B: No.

(A and $B$ sit down and play together).

The teacher listens to A and B's conversation and understands. The teacher understands and sympathizes with A's hurt feelings. Also, the teacher understands that B didn't hear A calling out for $\mathrm{B}$, and that $\mathrm{B}$ was trying to make it to dance practice on time. While doing so, the teacher leads $A$ to express A's feelings to B and confirms that B left first, not because B didn't want to wait, but because B didn't hear A. B starts to understand A's situation and feelings so A delivers and expresses how hurt A was to B for not waiting and asks to wait next time. $\mathrm{B}$ then agrees to wait next time and conflict resolves.

In this situation of $\mathrm{A}$ and $\mathrm{B}$, the teacher states that it's neither A nor B's fault, but that A and B are different. This acknowledges both A and B's identities and treating each other with respect by recognizing the difference in identities. Also, the feelings and emotions involved in that situation were sympathized with and respected. Then, A was mediated to express A's feelings. It can be seen that the conflict was resolved when the teacher recognized and mediated both $\mathrm{A}$ and B's different identities.

\subsubsection{Composition of Interdependency}

It defines Conflict generally as an expressed struggle between at least two interdependent parties who perceive incompatible goals, scarce resources, and interference from others in achieving their goals [8]. Conflict can be seen as a set of events created by participants. If participants are not interdependent, conflict is avoided due to absence of interference. A and B are in the same class, and they a part of the same after-school curricular activity so they are interdependent. First, in the conflict between A and B, there exists a goal that is in disagreement. The goal of wanting to go with a friend together, and the goal of that friend trying to avoid tardy are in disagreement. A thinks that leaving with A's friend B of higher importance while B thinks not being late as of higher importance. It can be seen that the conflict was formed due to the incompatibility of the two purposes. The feeling of respect and the feeling of $B$ leaving $A$ can be seen as incompatible. Tardiness is a result of having not enough and fixed time.

Due to limited time given to move classrooms, B couldn't wait for A, which resulted in a conflict. Interference resulting in tardiness means someone is halting another from reaching a goal or halting the access to resources. A wanted to handle the plane carefully but drops and cracks it because B rushed away while leaving A behind. The outcome of this is that A thinks B's not waiting for $A$ was an interference to A's ability to carefully handle and carry the plane. $\mathrm{B}$, on the other hand, thinks $A$ is interfering with B's desire to make it to dance practice on time by accusing and criticizing $B$ of not waiting for A. Conflict is a communicational collision, and the participants' expression of feelings is a form of communication. A conflict is formed by interdependent participants, and if the participants weren't interdependent they wouldn't interfere. So a communicational conflict arises because participants are interdependent. A conflict is formed cooperatively by participants, and definitely is not a problem of one individual but a joint problem of all.

\subsubsection{Unskilled Communication Skills}

As seen, the communication skills of a first grader can be poor. Jeon. Y. G. asserts that "Conflict Conversation is caused by criticism and it is occurred by disparaging peer or blaming of one's failure." [3]

In the example of A and B, A couldn't deliver the hurt feelings honestly and instead communicates by finding fault in B's actions and criticizes B for it. From B's perspective, A's accusation and criticism is disconcerted to B. But B doesn't share her disconcerted feeling, but only repeats that the reason B left is because B didn't want to be late. Then the teacher comes in and understands and sympathizes with A's feelings, which relieves A's frustration, which encourages A to share the hurt feelings honestly with $\mathrm{B}$ and tells $\mathrm{B}$ what A's desire is. A conflict was formed because the first graders were not able to share honestly how they felt regarding the situation but rather they tried to communicate by blaming the other person.

Communicating by recognizing other's emotions along with recognizing your own results in fair sympathy, which then compassionate communication is possible and mutual understandings form, while personal relationships are maintained [9]. As seen in the dialogue example, first graders lack expressing emotions and are at a lower level of communication skills, they need continuous practice. 


\section{Progression of Communicational Conflict}

Conflict between two students go through the process of competition, arbitration 1, arbitration 2, and recuperation. A and $\mathrm{B}$ focused on their identities but didn't give enough attention regarding each other's relationship. A believe that B's decision to not wait for $\mathrm{A}$ was equivalent to $\mathrm{B}$ disrespecting A. The one who betrays deliberately disappoints the other. Researchers Walter Jones and Marsha Parsons Burdette define betrayals as "violations of trust or expectations on which the relationship is based". [10] Also, A claims that the reason the plane cracked is because of B. In B's defense, B didn't hear A calling out for her, and the fact that A is blaming B for A's cracked plane, B has no choice but to disagree which results in both $\mathrm{A}$ and $\mathrm{B}$ repeating their opinions. This type of communication created two friends who ended up competing for no reason.

Then mediators intervene regarding the conflict and mediates A and B. C, A and B's friend, determines both A and $\mathrm{B}$ are at fault but the teacher, the other mediator, determines that neither are at fault and accepts both A and B. The teacher recognizes and accepts that $A$, who thinks moving together even if they are late, and B, who thinks punctuality is of higher importance, are experiencing different way of thinking. Also, the teacher sympathizes with A and B's emotions and leads both students to recognize and express their emotions. The mediation therefore is successful. The relationship between the two students is recovered as they accept each other's identity and character as well as sharing with each other their opinions.

\section{Conclusion}

The elementary students learned the following during a communicational conflict:

1. The students learned to express their emotions honestly. A decided to criticize the other student's actions rather than express one's emotions honestly, which resulted in a communicational conflict. Through the conflict, the students learned to resolve issues by sharing how they honestly feel inside.

2. The students learned that everyone thinks differently. Judging friends based on one's own values and blaming friends resulted in creating a conflict. The students learned, through the conflict, that what's important to one might not be as important to another.

3. The students learned that in a conflict, the ability to sympathize is important. The conflict was resolved when the teacher (mediator) mediated the students to recognize and sympathize each other's feelings. Through this step, the students learned that in communicating with others, it is important to sympathize and respect others' feelings.

The research on communicational conflict can be utilized to teach elementary students in communications by providing these implications:
1. It is important to teach the students in detail, how to express their emotions while being considerate of others at the same time. In current educational curriculum for first graders, it is vocabulary-centered. The system should teach, in addition to the current curriculum, how to express feelings and emotions while respecting the other.

2. Empathetic listening is crucial in resolving conflicts, therefore, while conversing with first grade students, it is important to have a discussion that revolves around empathy. Through this, the students should be guided to have empathetic communications naturally.

3. A teacher's role is important. Teachers not only mediate the students' communications, but also set an example on how to communicate. It is important that the teachers materialize on communication methods that are helpful to the students.

Instead of viewing conflicts that arise in communications as something negative, it is important to recognize them as events that are formed in the process of relationship creation. Conflicts not only pertains to competition but also pertains to showing an interest of the other person. Conflicts are not anyone's fault but something the two communicators interdependently create together, and are inevitable issues that form while identities are formed. Based on that, instead of perceiving conflicts as something negative or to avoid, conflicts should be seen as natural events that occur in communicating and should be taught on how to manage the conflicts. It is strongly believed that there needs more research on communicational conflict among elementary students.

\section{References}

[1] Kim. C. B. (2019). A Study on the Consciousness of Responses to Conflicts and the Education of Personality. Hankukeomunkyoyuk, 27. 59-88.

[2] Cho. J. Y. \& Seo. S. H. (2018). A Study on Conflict Recognition Survey in the Peer-to-Peer Communication Process of the First Grade Middle School Students, Journal of Learner- Centered Curriculum, 18 (9). 887-909.

[3] Jeon. Y. G. (2018). A Study of Education Contents for Conversational Strategies of Elementary School Students' Conflict Conversation: Focusing on Types of Conflict Conversation. Masteral Dissertation. Seoul National University of Education.

[4] Stewart. J., Zediker. k. \& Witteborn. S. (2005). Together, Communicating Interpersonally, A Social Construction Approach (6TH). Roxbury Pub Co, 318.

[5] Myers, G. E., \& M. T. Myers. (1985). The Dynamics of Human Communication: A Laboratory Approach, McGraw -Hill, Inc.

[6] Kim. Y. O. (2015). A Study on the conflicts of communication between the 1st grade elementary schoolchild and adult. Korean Education, 105, 74.

[7] Lee. C. D. (eds.) (2010). hwabeobkyoyukron (An Introduction to the Speaking-Listening Education), Seoul: Youkrack, 160. 
[8] Wilmot, W., and Hocker, J. (2001). Interpersonal Conflict, 6th ed, Boston; McGraw-Hill.

[9] Rogenberg, M. B. (2017). Nonvolent Commmunacation: A Language of Life. The Korean Center for Nonviolent Communication.
[10] Jones, W. W., and Burdetee, M. p. (1994). betrayal in relationships. In A. L. Weber and J. H. Harvey (eds.), Perspectives On Close Relationships. Boston: Allyn and Bacon, 244. 